\title{
Pathogen removal options: emphasizing SOLDIS for the filtrate of a GSAP Microflush toilet
}

\author{
S. Mecca ${ }^{1}$, B. Pellock ${ }^{2} \&$ R. Bretz ${ }^{1}$ \\ ${ }^{I}$ Department of Engineering-Physics-Systems, S-Lab, \\ Providence College, USA \\ ${ }^{2}$ Biology Department, Providence College, USA
}

\begin{abstract}
The Microflush toilet system, a low-flush off-grid macro-organism enhanced aerobic digester has been prototyped and shown to be an effective toilet solution for rural communities in the tropical developing world. The system rapidly filters solids in the waste stream from liquids - urine and greywater from hand washing. The solids are digested and vermi-composted with e. fetida and other macro-organisms resulting in high mass reduction and pathogen removal. The resulting compost is harvested every $2-3$ years. Successful field trials have been conducted on the system. This paper examines options for removing pathogens in the liquid filtrate. SOLDIS including solar thermal, UV and combination processes as well as SOLDIS-enhanced urine-ammonia treatment are examined. Dynamic models for SOLDIS thermal and UV processes have been developed in order to influence and study the effectiveness of alternative designs. Physical, economic and behavioral factors for each option are considered. Successful field trials will result in a virtually closed sustainable on-site sanitation solution with water used for handwashing, the resulting greywater used for micro-flushing, the blackwater processed to remove pathogens and the final solids product used for agriculture or other productive purposes with the entire process being off-grid.

Keywords: SOLDIS, SODIS, water purification, disinfection, Microflush, blackwater treatment.
\end{abstract}




\section{Introduction}

The Microflush toilet technology, which features an off grid, sustainable, low water flushing toilet and macro-organism enhanced digester, has been successfully deployed in field prototypes under a Grand Challenges Explorations award from the Bill \& Melinda Gates Foundation [1]. The system rapidly filters solids in the waste stream from liquids - urine and grey water from hand washing. The Microflush valve uses as little as $150 \mathrm{cc}$ of the handwash greywater for flushing. The solids are digested and vermi-composted with e. fetida and other macro-organisms resulting in high mass reduction and pathogen removal, a process that has proven to be superior to traditional latrine microbial composting [2]. The resulting compost is harvested every 2-3 years. In moving to the next generation of the system, the GSAP Microflush toilet (GMT), we are seeking to further refine the technology by studying disinfection alternatives for on-site processing of the small quantity of leachate. The options include Solar disinfection (SOLDIS). SOLDIS for drinking water has been widely studied and applied particularly in rural communities in the developing world [3]. Typically these applications have been inexpensive and simple, often consisting of recycled water bottles on a simple platform or structure, e.g. a used piece of corrugated roofing, exposed to the sun. Even semi-continuous systems have been proposed [4]. The application of simple decentralized SOLDIS technologies to the treatment of blackwater has been less widely considered. That is the focus of this paper. The full range of treatment options is beyond the scope of this paper, yet is part of the work of the S-Lab at Providence College to be published in a wider article. Basic systems analysis has been applied to identify the options, the template for which is shown in Table 1. A sample of Direct and Indirect SOLDIS, natural and artificial FILTER and CHEMICAL options are included. Systems may be designed in Batch, Semi-continuous or Continuous modes shown in the columns to the right.

Table 1: $\quad$ Systems' consideration of blackwater and greywater disinfection options.

\begin{tabular}{|c|c|c|c|c|c|}
\hline & & & Batch & Semi-Continuous & Continuous \\
\hline & & & & & \\
\hline SOLDIS & Direct & Thermal & & & \\
\hline & & UV & & & \\
\hline & & Combination & & & \\
\hline & Indirect & $\begin{array}{c}\text { Thermal } \\
\text { Enhancement }\end{array}$ & & & \\
\hline Filter & Natural & Clay & & & \\
\hline & & Sand & & & \\
\hline & Artificial & Osmotic & & & \\
\hline & & Other & & & \\
\hline CHEMICAL & Natural & Ammonia & & & \\
\hline & Artificial & Chlorine & & & \\
\hline & Combinations & Other & & & \\
\hline
\end{tabular}


Table 2 highlights a batch direct SOLDIS system combining thermal and UV disinfection and Table 3 indicates batch ammonia disinfection enhanced by a solar thermal process. There is ongoing work in our S-lab on the latter system using ammonia from urine combined with the blackwater filtrate.

The focus of this paper is on systems using thermal and UV SOLDIS for purifying blackwater leachate from a GSAP Microflush toilet (GMT).

Table 2: $\quad$ Thermal and UV direct SOLDIS system.

\begin{tabular}{|c|c|c|c|c|c|}
\hline & & & Batch & Semi-Continuous & Continuous \\
\hline & & & & & \\
\hline SOLDIS & Direct & Thermal & & & \\
\hline & & UV & & & \\
\hline & & Combination & & & \\
\hline & Indirect & $\begin{array}{c}\text { Thermal } \\
\text { Enhancement }\end{array}$ & & & \\
\hline Filter & Natural & Clay & & & \\
\hline & & Sand & & & \\
\hline & Artificial & Osmotic & & & \\
\hline CHEMICAL & Natural & Other & & & \\
\hline & Artificial & Chmonia & & & \\
\hline & Combinations & Other & & & \\
\hline
\end{tabular}

Table 3: $\quad$ SOLDIS thermal enhanced ammonia blackwater disinfection.

\begin{tabular}{|c|c|c|c|c|c|}
\hline & & & Batch & Semi-Continuous & Continuous \\
\hline \multirow[t]{4}{*}{ SOLDIS } & Direct & Thermal & & & \\
\hline & & UV & & & \\
\hline & & Combination & & & \\
\hline & Indirect & $\begin{array}{c}\text { Thermal } \\
\text { Enhancement }\end{array}$ & & & \\
\hline \multirow[t]{4}{*}{ Filter } & Natural & Clay & & & \\
\hline & & Sand & & & \\
\hline & Artificial & Osmotic & & & \\
\hline & & Other & & & \\
\hline \multirow[t]{3}{*}{ CHEMICAL } & Natural & Ammonia & & & \\
\hline & Artificial & Chlorine & & & \\
\hline & Combinations & Other & & & \\
\hline
\end{tabular}

\section{Direct SOLDIS}

As noted earlier, batch SOLDIS processing for drinking water can be as simple as a rack supporting one or more clear recycled or new PET bottles filled with water and exposed to the sun for a time sufficient to kill contaminant pathogens. Typical exposure times are 5-7 hours of direct sunlight in tropical clear day conditions $[4,5]$ for water of low turbidity. However, blackwater processing presents its own special problems. Leachate from a GMT can have turbidity of 40 NSB (Nephelometric Turbidity Units) or higher, which degrades the UV disinfection process though studies indicate persistent inactivation effects even at 
levels of 100 NTU and higher [6]. Further, batch processing would require attendant/family intervention vis a vis the handling of contaminated liquids in the course of operation of the toilet. Semi-continuous or continuous systems are desirable for blackwater processing.

\section{Model for SOLDIS}

A multi-segment dynamic model was developed in Stellat to represent UV and thermal kill of pathogens in a batch of contaminated water. (†Stella is a product of ISEE of Lebanon, NH USA.) The segments indicated in Figure 1 include thermal kill, UV kill, temperature/solar insolation and pathogen concentration. Figures 2 through 5 depict these structures within the model.

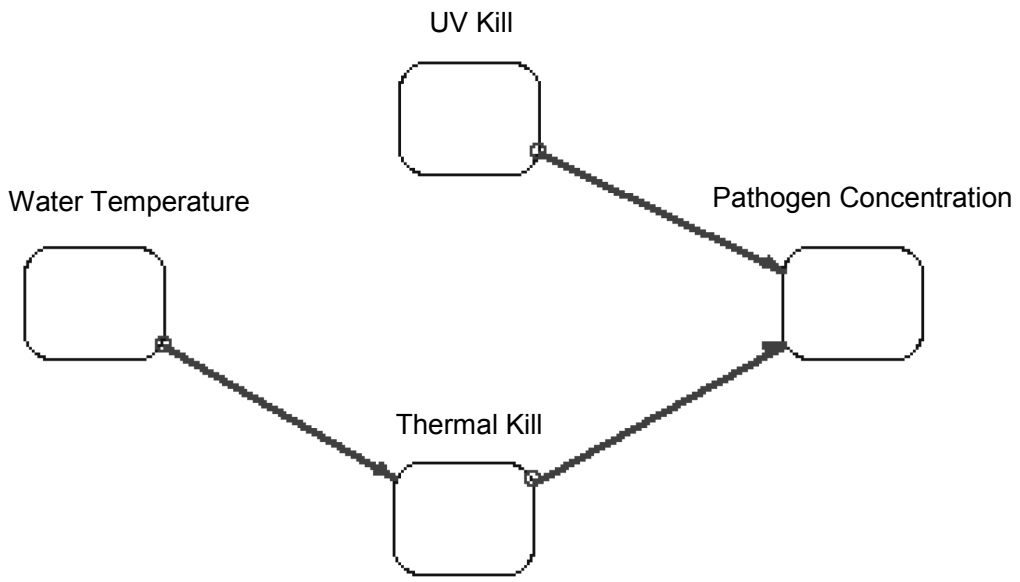

Figure 1: $\quad$ The SOLDIS model segments.

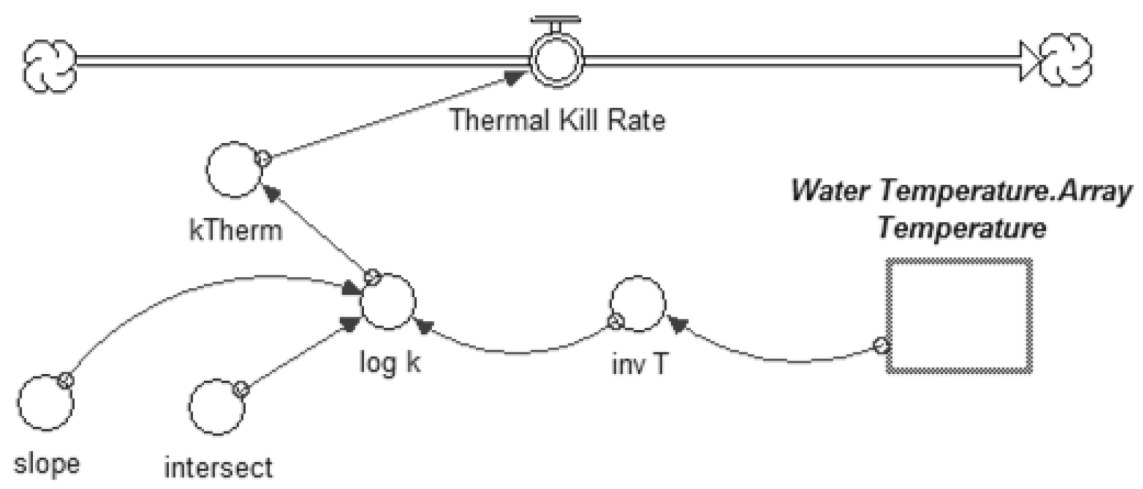

Figure 2: $\quad$ Thermal kill. 
The model will function for any specific pathogen where the UV dose and thermal kill rates are known. We have used a wild strain of fecal coli in our validation studies. While fecal coli serves as a marker pathogen for many studies, we recognize that there are far more resistant contaminants, e.g. ascaris, that can be found in human faeces and the resulting waste stream. Thermal kill rates are often expressed in time required at a given temperature to effect a factor of 10 kill (1D). These have been translated to an effective logical kill rate as a function of temperature, $\mathrm{k}(\mathrm{T})$, used in the model. The resulting $\mathrm{k}(\mathrm{T})$ has then been used in the model to verify known time-temperature combinations.

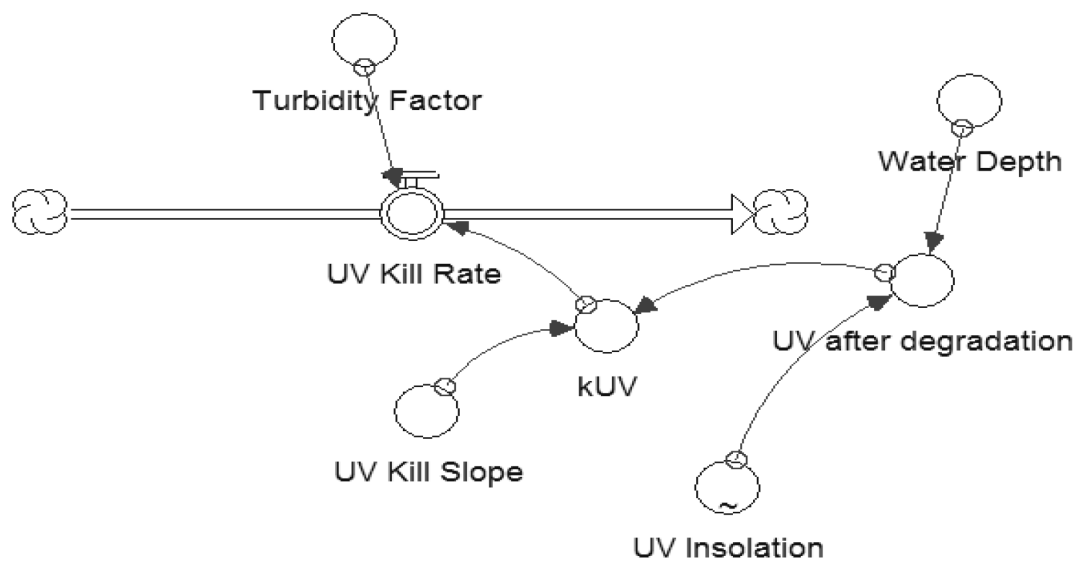

Figure 3: $\quad$ UV kill.

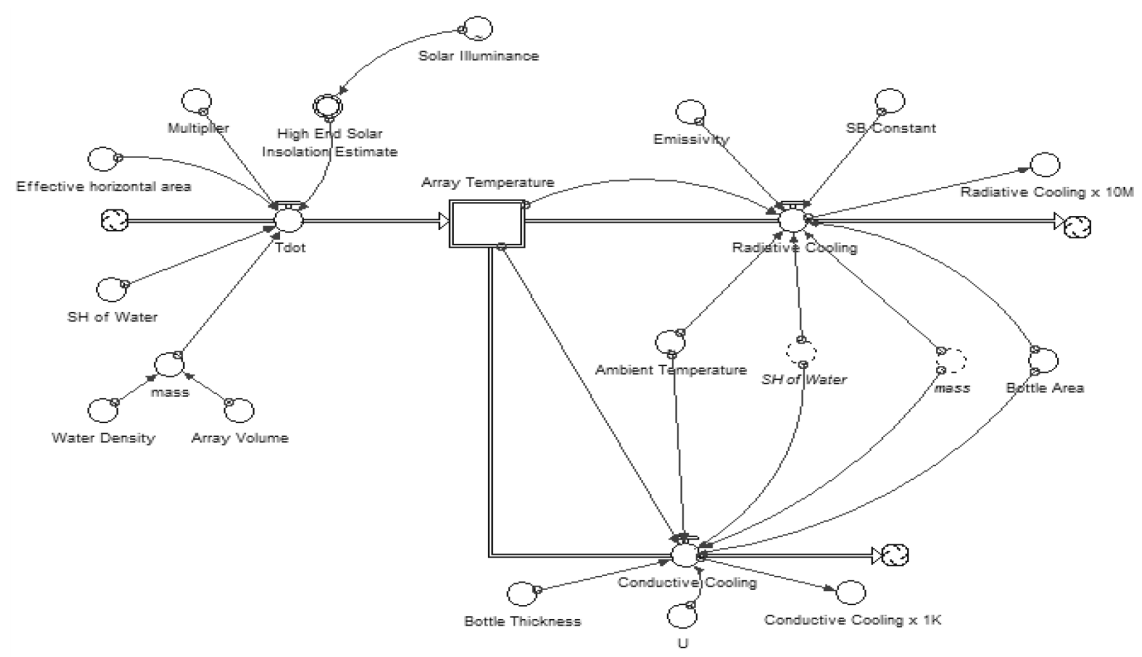

Figure 4: Temperature and insolation. 


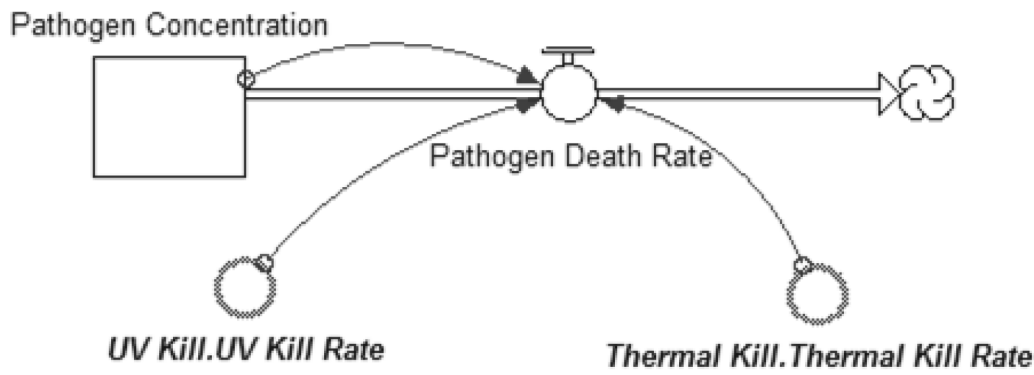

Figure 5: $\quad$ Pathogen concentration structure of the SOLDIS model.

\section{Model verification}

A suspension of a high concentration of Escherichia coli cells (a wild strain isolated from human feces) was prepared in $0.85 \% \mathrm{NaCl}$, used to fill a clean 1.5 liter water bottle, placed on a small rack, and exposed to sunshine in a parking lot near the S-lab (the experiment has been called the 'Parking L3ot experiment'). Measured were the ambient temperature, the temperature of the liquid, the solar insolation rate, UVA and UVB incident on the bottle. Six times during the course of the day of exposure, small samples of liquid were taken from the bottle and analyzed for viable cell counts. Since the samples contained too many viable cells to count directly, we measured the number of viable cells per millilitre using a dilution technique that allows viable cell counts to be quantified over more than seven orders of magnitude. In our dilution method, we prepared a series of dilutions of each sample and spotted $5 \mu$ of each dilution to a tryptic soy agar plate. The dilutions we used for spots numbered 1 through 10 on plates in Figure 6 were undiluted sample, 1/10, 1/100, 1/1,000, 1/10,000, $1 / 50,000,1 / 250,000,1 / 500,000,1 / 1,000,000$, and $1 / 2,000,000$ dilutions, respectively. Each viable cell within a dilution spot grows overnight at $37^{\circ} \mathrm{C}$ to form a single colony, allowing us to calculate the number of viable cells per $\mathrm{ml}$ in the undiluted sample.

Our control sample consisted of a bottle containing an E. coli suspension with a similar number of bacteria as the experimental treatment (compare plate in Figure $6 \mathrm{~A}$ to plate in Figure $6 \mathrm{G}$ ). The control sample was incubated at $22^{\circ} \mathrm{C}$ on a lab bench illuminated with standard fluorescent lighting, but no direct sunlight. The viable cell counts for the control sample were indistinguishable at the 9:30AM timepoint (data not shown) and the 4:30PM timepoint (Figure 6G), indicating that incubation in a saline suspension at $22^{\circ} \mathrm{C}$ had no effect on bacterial viability. In contrast, the Parking Lot experiment culture experienced a precipitous drop in viability between the 11:00AM and 1:00PM time points (compare Figure 6B to Figure 6C), with very few viable cells present in the culture from the 1:00PM time point through the end of the experiment (Figure 6C-F). 

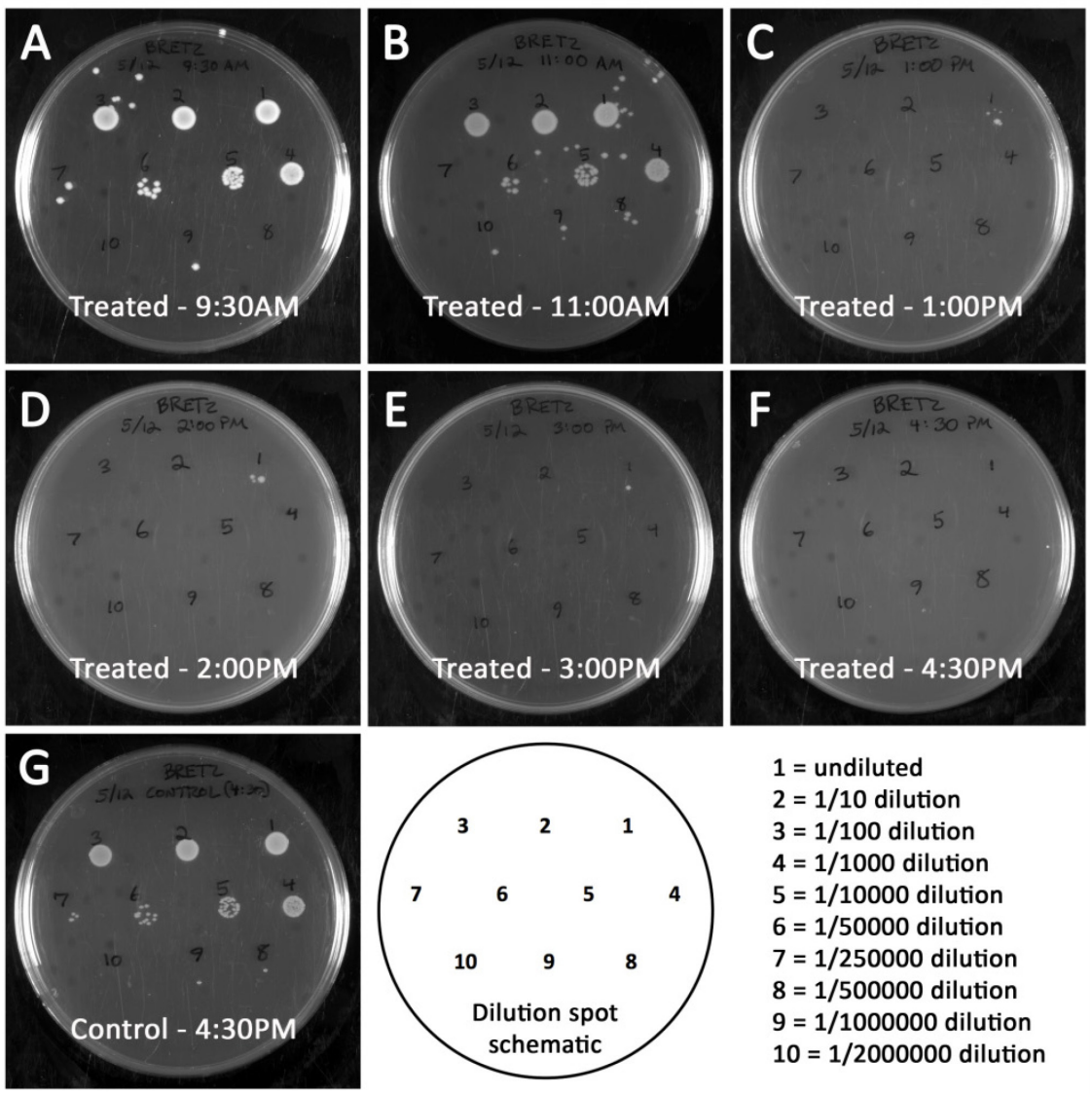

Figure 6: Data from parking lot experiment (May 12, 2011).

The experimental conditions (ambient temperature, bottle geometry and properties, insolation, UV rates, and initial pathogen concentration) were used to define parameters in the model and a simulation over the experimental time span was carried out. The results are shown in Figures 7 and 8 . Notice the early effect of UV and the eventual effect of thermal kill as the temperature increases in the course of the day. Figure 9 shows a comparison of the model simulation for cell count versus time with the results of the Parking Lot experiment. The model appears to capture the overall features of the kill especially during the period of the largest kill. Further, it gives a 2D kill over the course of the day even in this northern latitude spring sun parking lot. It is not surprising that batch SOLDIS with such a simple-inexpensive system functions so well in tropical communities where solar insolation rates, UV and corresponding array temperatures are much higher. 
UV Kill Rate $x 100000$

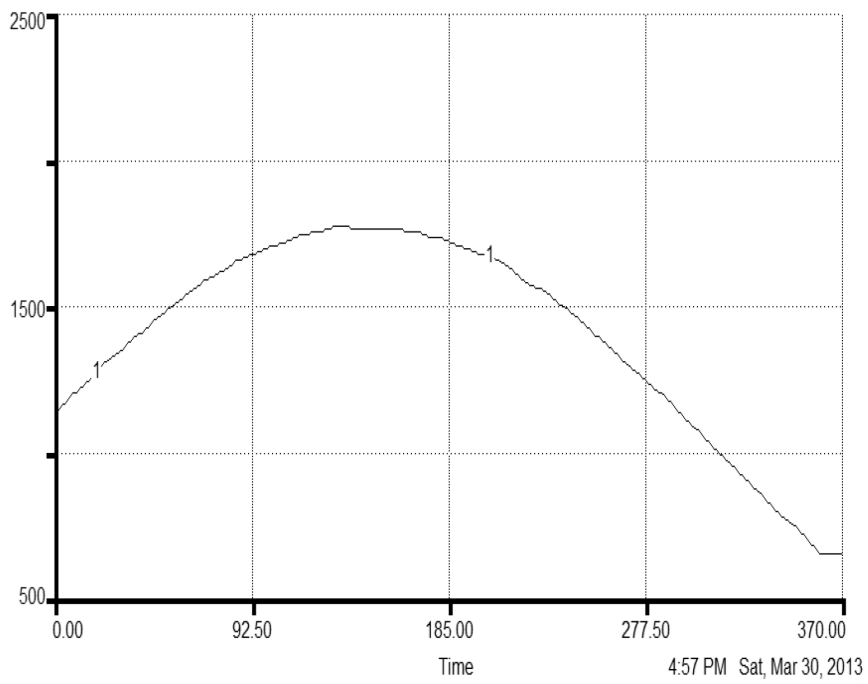

Figure 7: UV kill rate.

Thermal Kill Rate $x 100000$

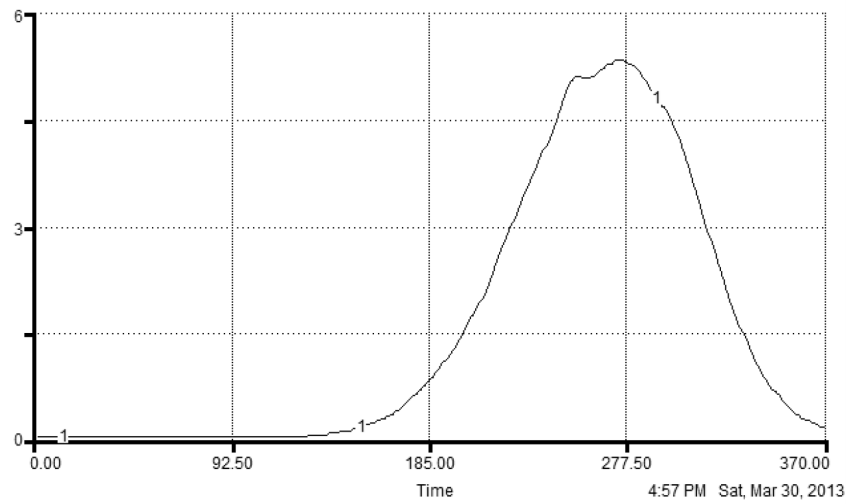

Figure 8: Thermal kill rate. Notice the relative scales (see text).

In fact, virtually all of the kill in this experiment was a result of the UV as can be seen in the scale of Figure 7 which shows the UV and thermal kill rates for the simulation. The UV kill rate is $350 \mathrm{x}$ the thermal kill rate. The peak temperature in the array was $45^{\circ} \mathrm{C}$ achieved well after solar noon as expected. This is the point at which thermal inactivation of e-coli becomes a factor [6]. 


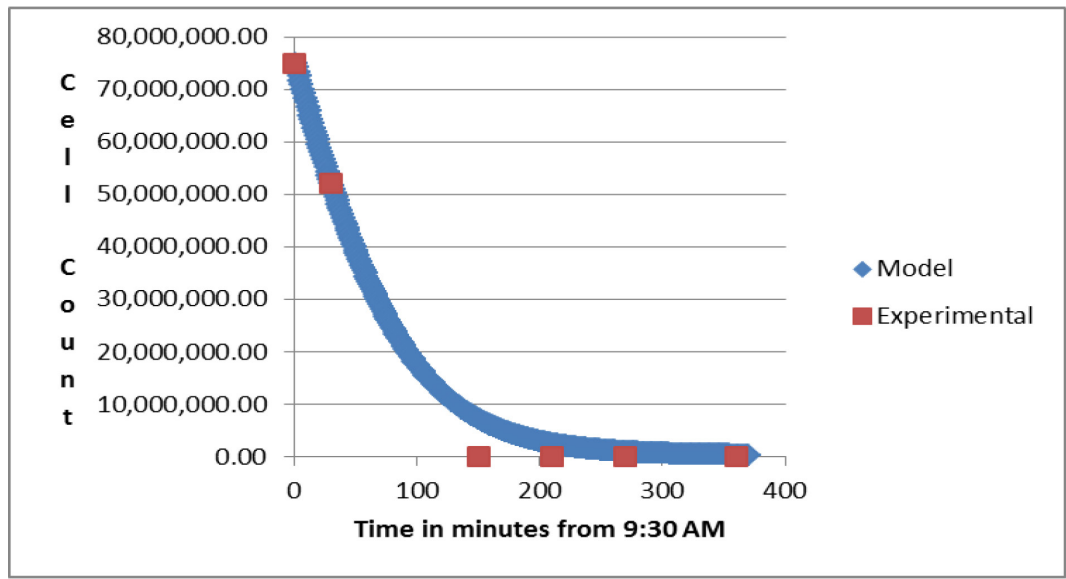

Figure 9: Model simulation results compared with experimental results from the "parking lot experiment".

\section{Blackwater SOLDIS}

Nevertheless, blackwater treatment using SOLDIS faces the aforementioned issue of turbidity-reducing UV kill. Turbidities in once-through blackwater in an S-Lab test digester are 40 NTU. This will impact field applications of SOLDIS and will require more dependence on thermal SOLDIS as a result of diminished UV kill. Further, there is the need to consider safe handling of the leachate especially in a blackwater batch process or (preferably) a semi-continuous or continuous process system.

We turn our attention to possibility of a semi- or continuous based system and, to get a handle on the design parameters, we consider the capacity required to treat a day's volume of leachate from a GMT system. Figure 10 depicts inputs and outputs of a GMT toilet for a single use. The GMT toilet uses the Microflush valve which flushes on as little as $150 \mathrm{cc}$ of water (greywater from hand washing). While there are time delays involved in the extraction of liquid from the faeces, the equilibrium filtrate release from a single use is just under $500 \mathrm{cc}$ most of which is urine. While the system can handle 30 uses in a day, the typical demand for a single household system is actually 15 uses per day and at this level the system functions predictively well. At this level, $\sim 8$ liters of liquid is produced and a continuous system of concatenated water bottles, for example, should involve 6 to 10 bottles of 1.5 liter volume to effect an expected 5D kill in tropical conditions and this requires a holding time of 5-6 hours on a typically sunny tropical day. Inexpensive continuous SOLDIS arrays are not common. Flores [4] proposes a semi continuous parallel array but a continuous system will best be supported with a serial array. An 8-bottle system was fabricated using ordinary water bottles joined end to end using roofing adhesive. The hope was 
to create a slow flowing turbulent fluid that would transit the array in 5-6 hours. Prior to construction, each cap was drilled in the center, the bottom of every other bottle was cut off and its mating bottle drilled at one side or the other (top or bottom), alternating every other bottle so as to create a relatively long flow path and a somewhat turbulent flow. The array was loaded from one end and when fully loaded and running, rhodamine dye was injected in the loading fluid which rate was set to keep the array full. The input and first elements (bottles) are shown in Figure 11.

What goes in:

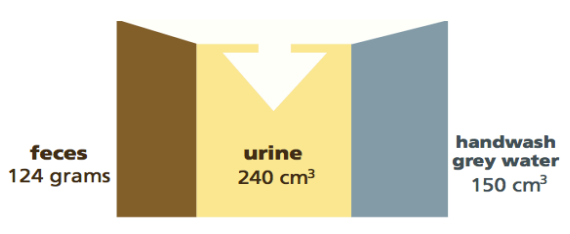

\section{What comes out:}

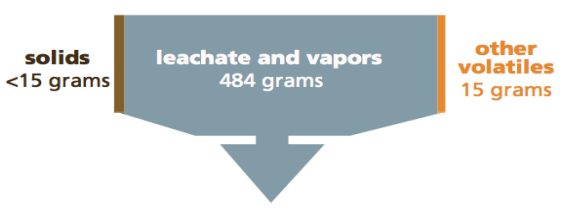

Figure 10: Inputs and outputs of a GMT toilet.

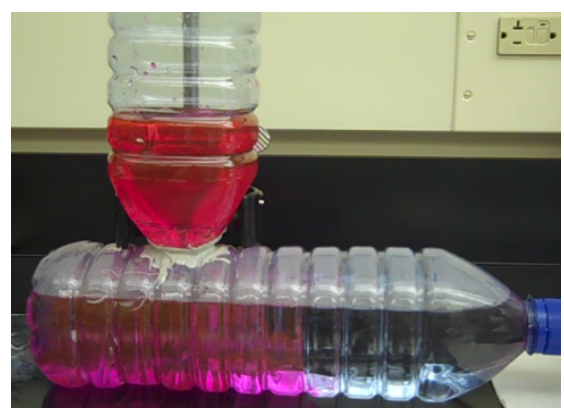

Figure 11: First elements of the test SOLDIS array showing the rhodamine dye progress.

The dye was tracked through the system and a fluorometer was used to test the outflow. The transit time so determined was found to be about 2.5 hours or about half of the time required for a continuous system to achieve the design concentration reduction. The result suggests that to effect the desired reduction, a similar system of twice the capacity is required. The space issues can be 
resolved by allowing one or more $180^{\circ}$ turns in the array, certainly doable from a construction vantage. Figure 12 is a sketch of such a serial array. Of course, actual dimensions and capacities will depend on the equilibrium turbidity of the leachate, though simple settling tanks can bring these to levels where UV will be a significant factor. Local weather conditions and seasonal extremes are clearly important.

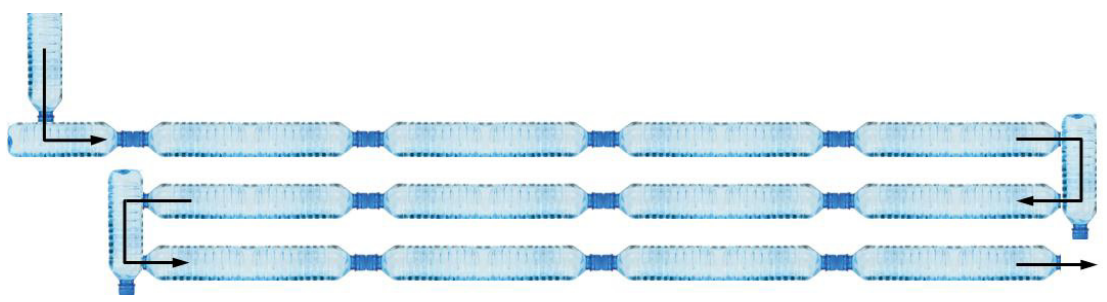

Figure 12: A possible configuration for a locally produced serial array for continuous SOLDIS processing of leachate from a GMT toilet.

The practically of such a system is of course an issue as the bottles will be subject to thermal and UV stresses affecting the lifetime. Further, there are the practical matters of physical security as such a system is a curious toy for children. Consideration of these is discussed in the next section.

\section{Other considerations}

There are many issues that must be taken into account before settling on a specific SOLDIS design. These include physical security, risk, material choices and, of course, costs, which are influenced by the design choices. The aforementioned concatenated recycled water bottles have the lowest up front material costs, but these can be flimsy and will require periodic replacement as the bottles themselves experience UV fatigue. One promising material with which we have been working is a plastic known as Platypus [8], which is used for storing small amounts of drinking water. Common sizes range from drinking bottle volumes to 6 liters. The flexible bags are easily placed in the sun Any SOLDIS array especially in a densely populated area becomes a toy for children and, if valuable materials are involved, a target for thievery. While one can imagine putting physical security in place, this will increase the costs and may impact performance if it involves any shading of the array.

As these are designs that would normally be constructed near the surface to allow for proper exposure to the sun, a material failure could result in contaminant exposure, a risk that must be accounted for with appropriate controls or mitigated through design enhancements. Going to an elevated surface, will involve pumping or manual lifting of batch leachate to that elevation, again with additional cost and/or risks associated with human handling of contaminated liquid.

Additional capacity for cloudy and rainy days must be incorporated into the design. 
Again, the platypus bags may offer a viable batch (and even semi-continuous) solution, especially if costs can be reduced; they can be readily moved to a secure (elevated) area for SOLDIS processing, are modular, easily carried and resistant to UV degradation. Further work is being carried out in our lab on this promising product.

It should be mentioned that two other options for blackwater disinfection are being aggressively studied in the S-Lab. Urine-ammonia disinfection and slow sand filters offer promising alternatives. As soon as lab-bench results are complete, we will apply cost-effectiveness models to basic engineering designs including batch, semi-continuous and continuous process versions.

\section{Conclusions}

SOLDIS, which has been used in developing tropical communities for purifying drinking water at the household level, offers an opportunity to remove pathogens from the small amount of filtrate blackwater from a GSAP Microflush toilet. This can be accomplished both directly through thermal and UV processes in either batch, semi-continuous or continuous SOLDIS designs.

While direct SOLDIS has been the focus of our work to date, we are beginning to realize the potential for indirect approaches, such as enhancing urine-provided ammonia disinfection. These and other methods, e.g. clay pot and slow sand filtering, also under investigation in our lab, offer the assurance that there are a plethora of options for adequate pathogen removal from the small amount of leachate from GSAP Microflush toilets to fit a wide range of environmental installation conditions. Analysis of affordable designs for these options now puts in sight the realization of an effective, off-grid, closed sanitation solution for the more than two billion people who lack access to an effective toilet and suffer the consequences in health, education, human dignity and lost opportunities for carrying on productive lives [9].

\section{References}

[1] Mecca, S., Davis, A. Davis, H., Application of GSAP Microflush toilets: a sustainable development approach to rural and peri-urban sanitation, ECOSUD 2013, WIT Press, UK, 2013.

[2] Hill, G. Baldwin, S., Vermicomposting toilets, an alternative to latrine style microbial composting toilets, prove far superior in mass reduction, pathogen destruction, compost quality and operational cost, Waste Management, Volume 32, Issue 10, October 2012, 1811-1820, Elsevier.

[3] McGuigan, K., Conroy, R., Mosler, H.J., du Preez, M., Ubomba-Jaswa, E., Fernandez-Ibañez, P. (2012). Solar water disinfection (SODIS): A review from bench-top to roof-top. Journal of Hazardous Materials, 235-236, 2946.

[4] Flores Cervantes, D. Feasibility of semi-continuous solar disinfection system for developing countries at a household level, Master of Engineering Thesis, MIT 2003. 
[5] Solar Water Disinfection. A guide for the application of SODIS. Swiss Federal Institute of Environmental Science and Technology. Department Water and Sanitation in Developing Countries. SANDEC Report No. 06/02, 2002.

[6] Fujioka, R.S., Yoneyama, B/S., Sunlight inactivation of human enteric viruses and fecal bacteria, Water Science and Technology Vol 46 No 11-12 pp 291-295 (C) IWA Publishing 2002.

[7] Berney M, Weilenmann HU, Simonetti A, Egli T., Efficacy of solar disinfection of Escherichia coli, Shigellaflexneri, Salmonella Typhimurium and Vibrio cholera, J Appl Microbiol., 2006 Oct;101(4): 828-36.

[8] Cascade Designs, Inc., http://cascadedesigns.com/platypus.

[9] Mecca, S., Davis, A., Davis, H., Observing how 'system unto system runs': WATSAN, Dignity, Health, Education and Opportunity, Water and Society, WIT Press, December 2011. 